\title{
The efficacy and safety of a novel method of peritoneal dialysis catheter insertion from the McBurney point
}

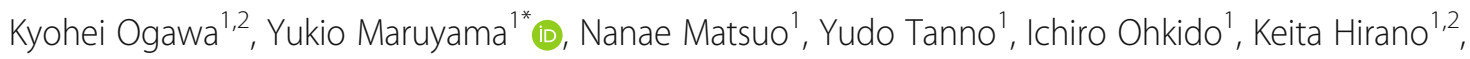
Masato Ikeda' and Takashi Yokoo ${ }^{1}$

\begin{abstract}
Background: Catheter dysfunction, especially omental wrapping, is a serious complication of peritoneal dialysis (PD). Although catheter implantation at a lower site was reported to prevent omental wrapping, this method could induce insufficient drainage of the PD solution and cause pain or a persistent desire to defecate, when the intraperitoneal catheter is of insufficient length or when its tip is in direct contact with the pelvic floor, respectively. The aim of this study was to assess the efficacy and safety of a novel PD catheter insertion method of approaching from the McBurney point, from the outer side of the abdomen.

Methods: This retrospective study included 23 patients with end-stage renal disease who were started on PD from January 2017 to July 2018 at Ashikaga Red Cross Hospital, Tochigi, Japan. Among them, 16 patients underwent a PD catheter insertion using a conventional method, whereas 7 patients underwent a novel method of approaching from the McBurney point. Infectious and mechanical complications were evaluated until August 2020.

Results: There were 18 men and 5 women, with a mean age of $63.1 \pm 13.6$ years. All patients were followed up postoperatively for a mean duration of $27.2 \pm 13.4$ months. No patient experienced omental wrapping, insufficient drainage of the PD solution, and pain or persistent desire to defecate in both groups. Both the incidence of infectious and mechanical complications (times per patient-year) were not statistically different between patients undergoing a conventional and a novel PD catheter insertion ( 0.18 vs. $0.24 ; p=0.79$ and 0.03 vs. $0.16 ; p=0.16$, respectively).
\end{abstract}

Conclusions: This novel method of PD catheter insertion from the McBurney point was safe, caused less discomfort, and was effective in preventing catheter dysfunction.

Keywords: Catheter, Catheter dysfunction, Catheter migration, Omental wrapping, Peritoneal dialysis

\footnotetext{
* Correspondence: maruyama@td5.so-net.ne.jp

'Division of Nephrology and Hypertension, Department of Internal Medicine,

The Jikei University School of Medicine, 3-25-8 Nishi-shinbashi, Minato-ku,

Tokyo 105-8471, Japan

Full list of author information is available at the end of the article
}

(c) The Author(s). 2020 Open Access This article is licensed under a Creative Commons Attribution 4.0 International License, which permits use, sharing, adaptation, distribution and reproduction in any medium or format, as long as you give appropriate credit to the original author(s) and the source, provide a link to the Creative Commons licence, and indicate if changes were made. The images or other third party material in this article are included in the article's Creative Commons licence, unless indicated otherwise in a credit line to the material. If material is not included in the article's Creative Commons licence and your intended use is not permitted by statutory regulation or exceeds the permitted use, you will need to obtain permission directly from the copyright holder. To view a copy of this licence, visit http://creativecommons.org/licenses/by/4.0/. The Creative Commons Public Domain Dedication waiver (http://creativecommons.org/publicdomain/zero/1.0/) applies to the data made available in this article, unless otherwise stated in a credit line to the data. 


\section{Background}

Peritoneal dialysis (PD) is an established renal replacement therapy in patients with end-stage renal disease (ESRD) [1]. However, mechanical complications, such as catheter dysfunction, can increase medical costs and reduce patient confidence. In addition, repeat operation can increase the psychological stress and physical pain of patients. Workeneh et al. [2] reported that catheter dysfunction accounted for $18 \%$ of the causes of PD withdrawal among 128 incident PD patients in the USA. One of the most frequent causes of PD catheter dysfunction necessitating intervention is omental wrapping [3]. Weber et al. [4] reported that 8 of 138 incident PD patients $(6 \%)$ presented with catheter dysfunction secondary to omental wrapping within 1 year. Recently, several approaches have been attempted to reduce the incidence of omental wrapping. Two studies reported that implanting the catheter at a lower site on the paramedial area above the pubic symphysis completely prevented omental wrapping $[5,6]$. However, these studies did not clarify the incidence of post catheter insertion discomfort, including pelvic floor pain or persistent desire to defecate, considering that implantation of the catheter at a lower site could induce direct contact between the catheter tip and the pelvic floor. In addition, this method could induce insufficient drainage of the PD solution because of the shorter length of the intraperitoneal catheter. Indeed, the reported insertion point by Zhang et al. was on a paramedian site, from 4.5 to $5.5 \mathrm{~cm}$ above the pubic symphysis [6]. Therefore, we hypothesized that implanting the catheter in the pelvic cavity from the outside of the abdomen can maintain a sufficient length of the intraperitoneal catheter and reduce the risk for insufficient drainage of the PD solution.

The aim of this retrospective study was to assess the efficacy and safety, including catheter dysfunction and experience of pain or persistent desire to defecate, of a novel PD catheter insertion method of approaching from the McBurney point, which is one of the most recognizable landmarks outside the abdomen.

\section{Methods}

From January 2017 to July 2018, 23 ESRD patients were started on PD at the Ashikaga Red Cross Hospital, Tochigi, Japan. Among them, 16 patients underwent a PD catheter insertion using a conventional method, whereas 7 patients underwent a novel method of approaching from the McBurney point. The ethics committee at the Ashikaga Red Cross Hospital approved this study protocol. Written informed consent was not required because of the non-interventional and retrospective chart review design. All individual participants were provided a means to opt out in this study. The study proceeded in accordance with the Declaration of
Helsinki. All surgeries were performed by the same group of nephrologists and surgeons. Double-cuffed swan neck catheter was used in all cases. The total length of the catheter was $40 \mathrm{~cm}$, and the distance from the deep cuff to the tip was $13.5 \mathrm{~cm}$. Antibiotic prophylaxis with cefazolin was given within $1 \mathrm{~h}$ prior to the surgical incision.

Operative procedures of a novel method of approaching from the McBurney point were as follows. The laparoscopic catheter placement procedure employed was a 1-port technique. Pneumoperitoneum was induced using a Veress needle, which was inserted at the infraumbilical region through a $5-\mathrm{mm}$ longitudinal skin incision. The abdomen was insufflated with carbon dioxide to maintain an intraabdominal pressure of 10 $\mathrm{mmHg}$ during surgery. One 5-mm metal trocar was inserted into the peritoneal cavity through the initial Veress needle position, and preliminary laparoscopy was performed to explore for potential adhesions or other anatomic anomalies that could impede catheter placement.

A 2-cm longitudinal skin incision was made on a marked skin at the McBurney point, a point on the line from the umbilicus to the anterior superior iliac spine, $2 / 3$ of the distance from the umbilicus to the iliac spine. The insertion point was adjusted in such a way that the catheter can be placed from the surface of the body and the catheter tip was located in the pubic symphysis. The subcutaneous fat was bluntly dissected under direct vision, followed by careful dissection of the muscle fibers to avoid injury to the vessels. A $1-\mathrm{cm}$ incision into the peritoneal cavity was created through the peritoneum under laparoscopic visualization, followed by insertion of the catheter. The tip of the catheter was placed in the pouch of Douglas. Thereafter, the peritoneum was ligated using a purse-string suture on the lower edge of the inner cuff, and the fascia was closed. A curved tunnel was used to create an exit site on the area of the right hypochondrium. The laparoscope was reinserted to check for hematoma and to ensure a correct location of the catheter tip inside the pelvis. Afterwards, the camera was removed, and the pneumoperitoneum was gradually released. Eventually, after removal of the 5-mm trocars, all wounds were sealed in layers (Fig. 1). A representative abdominal X-ray after catheter insertion is shown in Fig. 2. Complete PD was started after 1 week to permit adequate time for complete wound healing.

On the other hand, operative procedures of conventional methods were as follows. Under local anesthesia, a 5 -cm longitudinal skin incision was made on approximately $2-3 \mathrm{~cm}$ below the navel, subcutaneous tissue was separated, and the anterior rectus sheath was dissected then performed to expose the posterior rectus sheath. An incision is made in the posterior sheath and 


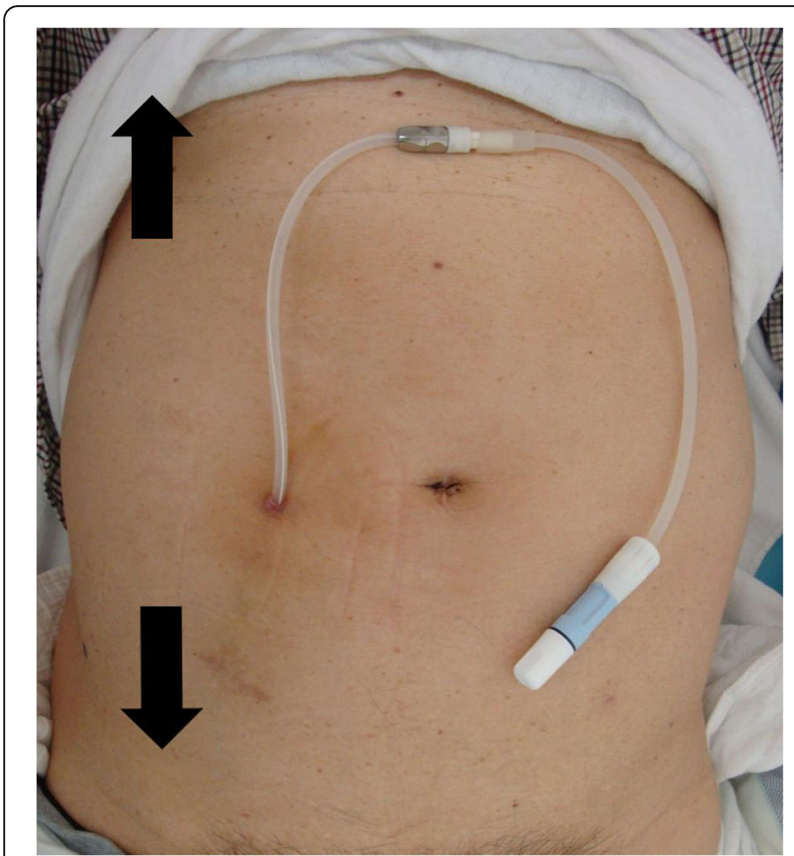

Fig. 1 External view of peritoneal dialysis catheter placement. The head and end caudal side were indicated by upward- and downward-pointing arrows, respectively

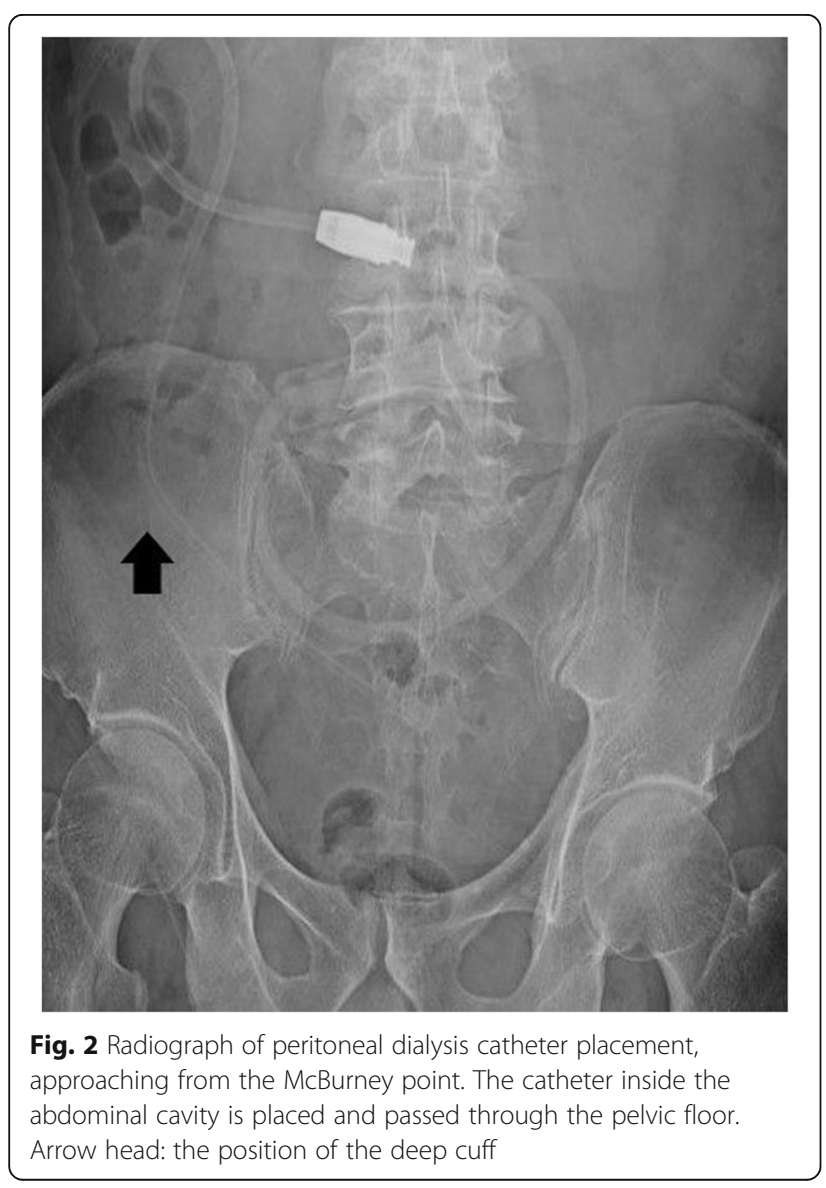

peritoneum to reach the abdominal cavity. When the tip of the catheter reaches the Douglas fossa, the catheter cuff and peritoneum were ligated using a purse-string suture, and the fascia was closed. A curved tunnel was used to create an exit site on the area of the hypochondria.

We asked the patients if they felt the pelvic floor pain or persistent desire to defecate. Infectious and mechanical complications were evaluated until August 2020. Infectious complications were defined as episode of tunnel infection and peritonitis, and mechanical complications were defined as episode of catheter migration, pericatheter leakage, hernia, and omental wrapping.

Data are presented as mean \pm standard deviation. The difference of incidence of infectious and mechanical complications (times per patient-year) was analyzed using Fisher's exact test. Data were statistically analyzed using JMP for Windows version 13.2.1 (SAS Institute, Cary, NC).

\section{Results}

Table 1 shows the patient characteristics and outcomes. There were 18 men and 5 women included, with a mean age of $63.1 \pm 13.6$ years. The cause of ESRD was diabetes in 9, hypertension in 6, chronic glomerulonephritis in 4, and other or unknown in 4 cases. Four patients, 3 in the conventional method group and 1 in the novel method group, had a history of abdominal surgery. Mean body mass index was $23.8 \pm 4.3 \mathrm{~kg} / \mathrm{m}^{2}$. The mean postoperative follow-up period was $27.2 \pm 13.4$ months. One patient (case 7) developed PD-associated peritonitis secondary to a tunnel infection caused by Staphylococcus aureus after 6 months of the PD initiation. After removal of the PD catheter, she wanted to transfer to hemodialysis. One patient (case 1) developed catheter migration 1 week after the operation, but he was able to continue $\mathrm{PD}$, because both infusion and drainage of the solution were not impaired. Although pericatheter leakage of the PD solution 1 week after the operation was seen in 1 patient (case 5), it resolved spontaneously; however, this patient developed cerebral hemorrhage 9 months after starting PD and was switched to hemodialysis because of difficulty in continuing PD. There was no patient who experienced pain or persistent desire to defecate, insufficient drainage of the PD solution, or omental wrapping. Both the incidence of infectious and mechanical complications (times per patient-year) were not statistically different between patients undergoing a conventional and a novel $\mathrm{PD}$ catheter insertion ( 0.18 vs. $0.24 ; p=0.79$ and 0.03 vs. $0.16 ; p=0.16$, respectively). 
Table 1. Patient characteristics and outcome

\begin{tabular}{|c|c|c|c|c|c|c|c|c|c|c|}
\hline Group & No. & Sex & Age & $\begin{array}{l}\text { Etiology } \\
\text { of ESRD }\end{array}$ & BMI $\left[\mathrm{kg} / \mathrm{m}^{2}\right]$ & $\begin{array}{l}\text { History of } \\
\text { abdominal surgery }\end{array}$ & $\begin{array}{l}\text { Follow-up period } \\
\text { (month) }\end{array}$ & $\begin{array}{l}\text { Infective } \\
\text { complications }\end{array}$ & $\begin{array}{l}\text { Mechanical } \\
\text { complications }\end{array}$ & Outcome \\
\hline \multicolumn{11}{|c|}{ Patients underwent a PD catheter insertion with a novel method. } \\
\hline & 1 & Male & 70 & Hypertension & 26.2 & No & 33 & No & $\begin{array}{l}\text { Catheter } \\
\text { migration }\end{array}$ & Continue PD \\
\hline & 2 & Male & 61 & Diabetes & 21.6 & No & 32 & No & No & Continue PD \\
\hline & 3 & Male & 68 & Hypertension & 21.2 & No & 32 & PD peritonitis & No & Continue PD \\
\hline & 4 & Female & 60 & Diabetes & 18.8 & No & 14 & PD peritonitis & No & $\begin{array}{l}\text { Transfer HD } \\
\text { due to } \\
\text { overhydration }\end{array}$ \\
\hline & 5 & Male & 56 & Diabetes & 29.6 & No & 9 & No & $\begin{array}{l}\text { Pericatheter } \\
\text { leakage }\end{array}$ & $\begin{array}{l}\text { Transfer HD } \\
\text { due to } \\
\text { cerebral } \\
\text { bleeding }\end{array}$ \\
\hline & 6 & Male & 46 & Diabetes & 31.4 & No & 26 & No & No & Continue PD \\
\hline & 7 & Female & 77 & Diabetes & 26.7 & Yes & 6 & $\begin{array}{l}\text { PD peritonitis } \\
\text { secondary to a } \\
\text { tunnel } \\
\text { infection }\end{array}$ & No & $\begin{array}{l}\text { Transfer HD } \\
\text { due to PD } \\
\text { peritonitis }\end{array}$ \\
\hline \multicolumn{11}{|c|}{ Patients underwent a PD catheter insertion with a conventional method } \\
\hline & 8 & Male & 51 & Unknown & 25.7 & No & 18 & PD peritonitis & No & $\begin{array}{l}\text { Transfer HD } \\
\text { due to } \\
\text { overhydration }\end{array}$ \\
\hline & 9 & Male & 44 & CGN & 23.5 & No & 27 & PD peritonitis & No & Continue PD \\
\hline & 10 & Male & 79 & Diabetes & 22.0 & No & 32 & PD peritonitis & No & Death \\
\hline & 11 & Female & 60 & CGN & 16.3 & Yes & 43 & No & No & Continue PD \\
\hline & 12 & Male & 91 & Hypertension & 22.6 & No & 4 & No & No & Death \\
\hline & 13 & Male & 68 & Diabetes & 25.1 & No & 42 & PD peritonitis & $\begin{array}{l}\text { Pericatheter } \\
\text { leakage }\end{array}$ & Continue PD \\
\hline & 14 & Female & 82 & Unknown & 23.3 & No & 40 & No & No & Continue PD \\
\hline & 15 & Male & 51 & CGN & 20.1 & No & 39 & No & No & Continue PD \\
\hline & 16 & Male & 43 & Unknown & 18.2 & Yes & 5 & PD peritonitis & No & $\begin{array}{l}\text { Death due to } \\
\text { PD-associated } \\
\text { peritonitis }\end{array}$ \\
\hline & 17 & Male & 71 & Diabetes & 22.3 & No & 4 & PD peritonitis & No & $\begin{array}{l}\text { Transfer HD } \\
\text { due to PD- } \\
\text { associated } \\
\text { peritonitis }\end{array}$ \\
\hline & 18 & Male & 80 & Unknown & 30.8 & Yes & 33 & No & No & $\begin{array}{l}\text { Death due to } \\
\text { lung cancer }\end{array}$ \\
\hline & 19 & Male & 53 & Hypertension & 23.3 & No & 39 & No & No & Continue PD \\
\hline & 20 & Female & 65 & CGN & 17.0 & No & 38 & PD peritonitis & No & Continue PD \\
\hline & 21 & Male & 77 & Hypertension & 23.8 & No & 38 & No & No & Continue PD \\
\hline & 22 & Male & 57 & Hypertension & 27.9 & No & 38 & No & No & Continue PD \\
\hline & 23 & Male & 41 & Diabetes & 30.2 & No & 34 & No & No & Continue PD \\
\hline
\end{tabular}

ESRD end-stage renal disease, $B M I$ body mass index, $P D$ peritoneal dialysis, $H D$ hemodialysis, $C G N$ chronic glomerulonephritis

\section{Discussion}

In the present study, we demonstrated the benefit of a novel method of PD catheter implantation from the McBurney point. In all cases, there was no episode of peritonitis, exit site infection, visceral injury, or significant hemorrhage within 1 month of the catheter insertion. Although the comparisons between patients receiving conventional and novel catheter insertion methods were difficult because of the small numbers of patients, there was no significant difference in the incidence of infectious and mechanical complications. As suggested by the International Society for Peritoneal 
Dialysis (ISPD) guideline, the specific clinical goals for a PD access procedure [7] were $<5 \%$ incidence of exit site/tunnel infection or peritonitis and $<1 \%$ incidence of visceral injury or significant hemorrhage requiring transfusion or surgical intervention within 30 days of the catheter insertion. Although 1 patient developed catheter migration and another patient developed pericatheter leakage at 1 week after the operation, both cases resolved without any intervention. Of note, no patient developed omental wrapping or experienced pain or persistent desire to defecate.

In approximately 250 institutions in Japan, PD catheter implantation has been performed by nephrologists in $30 \%$, non-nephrologists in $52.4 \%$, and by both in $17.6 \%$ [8]. At our institution, this operation is undertaken by nephrologists and surgeons for warranty of safety. Because the McBurney point is one of the most famous body surface markers, it is easy to understand and achieve standardization of the surgical procedure especially for non-nephrologists. In addition, according to a systematic review, laparoscopic surgery was superior to traditional open surgery in reducing catheter migration and prolonging catheter survival rate [9]. In particular, the use of laparoscopic surgery was reported to be effective in salvaging malfunctioning PD catheters $[3,10]$. In the ISPD guideline, a design with $15 \mathrm{~cm}$ of tubing length beyond the deep cuff was recommended [7]. In this design, a point $5 \mathrm{~cm}$ from the tip of the catheter is aligned with the pubic symphysis upper border. Indeed, we always used the catheter whose distance from the deep cuff to the tip was approximately $15 \mathrm{~cm}$. However, this type of catheter is not suitable in many cases for average Japanese body size in the surgical procedure approached from McBurney point. Therefore, we selected the different catheter whose distance from the deep cuff to the tip was approximately $13.5 \mathrm{~cm}$ and confirmed that the tip of the catheter was at the right position.

Although the navel has been traditionally used as a body surface marker of the incision site, the distance from the navel to the pouch of Douglas varies according to the physique. In particular, the tendency for a higher catheter insertion site in a taller patient can increase the incidence of omental wrapping. The pubic symphysis has been recommended as a reliable reference for the ideal location of the catheter tip on the upper part of the true pelvis [7]. To reduce the incidence of omental wrapping, one possible approach is to implant the catheter on a lower site; this approach was reported to have $0 \%$ incidence of omental wrapping, compared with the $7.6 \%$ incidence after a traditional surgical procedure $[5,6]$.

However, a surgical incision that is too low might cause other problems [11]. First, low insertion of the catheter can induce direct contact between the catheter tip and the pelvic floor and may cause discomfort, including pelvic floor pain or persistent desire to defecate. Second, at a level of $4-5 \mathrm{~cm}$ below the umbilicus, the posterior abdominal oblique aponeurosis and the transversus tendon are directed all the way to the anterior rectus abdominis to form a sheath; this leads to the absence of a rectus sheath posteriorly. In such a case, the peritoneum at this level is relatively weak, and low catheter insertion could lead to PD fluid leakage. Third, this method could induce insufficient drainage of the PD solution because of the shorter length of the intraperitoneal catheter. In our cases, we implanted the catheter into the pelvic cavity from the outside of the abdomen in order to keep a sufficient length of the intraperitoneal catheter. As a result, no patient experienced insufficient drainage of the PD solution.

There were serious limitations to the present study. Since the number of cases was very small, the comparisons between patients receiving conventional and novel catheter insertion methods were difficult. Second, the observational design allowed only limited conclusions.

\section{Conclusions}

In this case series, we found that a novel PD catheter insertion method of approaching from the McBurney point was safe and effective in preventing catheter dysfunction. Additionally, this method could facilitate the procedure for non-nephrologists, because the McBurney point is one of the most famous body surface markers. To prove the effectiveness of this novel method and to clarify the optimal type of catheter and insertion point, a controlled study on a larger number of patients will be needed.

\section{Abbreviations}

PD: Peritoneal dialysis; ESRD: End-stage renal disease; ISPD: International Society for Peritoneal Dialysis

\section{Acknowledgements}

Not applicable.

\section{Ethical approval and consent to participate}

The ethics committee at the Ashikaga Red Cross Hospital approved this study protocol. Written informed consent was not required because of the non-interventional and retrospective chart review design. All individual participants were provided a means to opt out in this study.

\section{Authors' contributions}

Research idea and study design: K.O., Y.M., N.M., Y.T., I.O., K.H., and M.I; data acquisition: K.O. and K.H; data analysis/interpretation: K.O. and Y.M.; statistical analysis: Y.M.; supervision or mentorship: T.Y. Y.M. takes responsibility that this study has been reported honestly, accurately, and transparently and accepts accountability for the overall work by ensuring that questions pertaining to the accuracy or integrity of any portion of the work are appropriately investigated and resolved. The authors read and approved the final manuscript. 
Funding

This research received no specific grant from any funding agency in the public, commercial, or not-for-profit sectors.

\section{Availability of data and materials}

The datasets used and/or analyzed during the current study are available from the corresponding author on reasonable request.

\section{Consent for publication}

Not applicable.

\section{Competing interests}

Y.M. and M.I. received scholarship funds from Baxter International, Inc. and Terumo Corporation. Y.T. received research grants from Baxter International, Inc. No sources of funding had any direct involvement in the design or conduct of the study; in the collection, management, analysis, or interpretation of data; or in the preparation, review, or approval of the manuscript. No other authors have any conflicts of interest to declare.

\section{Author details}

'Division of Nephrology and Hypertension, Department of Internal Medicine, The Jikei University School of Medicine, 3-25-8 Nishi-shinbashi, Minato-ku, Tokyo 105-8471, Japan. ${ }^{2}$ Division of Nephrology, Department of Internal Medicine, Ashikaga Red Cross Hospital, Tochigi, Japan.

Received: 19 June 2020 Accepted: 23 November 2020

Published online: 30 November 2020

\section{References}

1. Gokal R. CAPD overview. Perit Dial Int. 1996;16(Suppl 1):S13-8.

2. Workeneh B, Guffey D, Minard CG, Mitch WE. Causes for withdrawal in an urban peritoneal dialysis program. Int J Nephrol. 2015;2015:652953.

3. Santarelli S, Zeiler M, Marinelli R, Monteburini T, Federico A, Ceraudo E. Videolaparoscopy as rescue therapy and placement of peritoneal dialysis catheters: a thirty-two case single centre experience. Nephrol Dial Transplant. 2006;21(5):1348-54.

4. Weber J, Mettang T, Hubel E, Kiefer T, Kuhlmann U. Survival of 138 surgically placed straight double-cuff Tenckhoff catheters in patients on continuous ambulatory peritoneal dialysis. Perit Dial Int. 1993;13(3):224-7.

5. Li Y, Zhu Y, Liang Z, Zheng X, Zhang H, Zhu W. A simple modified open peritoneal dialysis catheter insertion procedure reduces the need for secondary surgery. International urology and nephrology. 2019;51(4):729-36.

6. Zhang L, Liu J, Shu J, Hu J, Yu X, Mao H, et al. Low-site peritoneal catheter implantation decreases tip migration and omental wrapping. Perit Dial Int. 2011;31(2):202-4.

7. Crabtree JH, Shrestha BM, Chow KM, Figueiredo AE, Povlsen JV, Wilkie M, et al. Creating and maintaining optimal peritoneal dialysis access in the adult patient: 2019 update. Perit Dial Int. 2019:39(5):414-36.

8. Ikeda M, Terawaki H, Kanda E, Furuya M, Tanno Y, Nakao M, et al. Interventional nephrology: current status and clinical impact in Japan. Clin Exp Nephrol. 2018;22(2):437-47.

9. Qiao Q, Zhou L, Hu K, Xu D, Li L, Lu G. Laparoscopic versus traditional peritoneal dialysis catheter insertion: a meta analysis. Renal failure. 2016; 38(5):838-48.

10. Ogunc G. Malfunctioning peritoneal dialysis catheter and accompanying surgical pathology repaired by laparoscopic surgery. Perit Dial Int. 2002; 22(4):454-62.

11. Crabtree JH, Chow KM. Peritoneal dialysis catheter insertion. Seminars in nephrology. 2017;37(1):17-29.

\section{Publisher's Note}

Springer Nature remains neutral with regard to jurisdictional claims in published maps and institutional affiliations.

Ready to submit your research? Choose BMC and benefit from:

- fast, convenient online submission

- thorough peer review by experienced researchers in your field

- rapid publication on acceptance

- support for research data, including large and complex data types

- gold Open Access which fosters wider collaboration and increased citations

- maximum visibility for your research: over $100 \mathrm{M}$ website views per year

At $\mathrm{BMC}$, research is always in progress.

Learn more biomedcentral.com/submissions 